\title{
Application of purge and trap extraction and gas chromatography for determination of minor esters in cider
}

\author{
Roberto Rodríguez Madrera*, Noemí Palacios García, Ana García Hevia, Belén Suárez Valles \\ Área de Tecnología de los Alimentos, Servicio Regional de Investigación y Desarrollo Agroalimentario (SERIDA), Departamento de \\ Sidrea y Derivados, Carretera de Oviedo s/n, 33300 Villaviciosa, Asturias, Spain
}

Received 18 November 2004; received in revised form 31 January 2005; accepted 9 February 2005

\begin{abstract}
The validation of a method based on the purge and trap technique combined with gas chromatography-mass spectrometry-flame ionization detection has been carried out in order to apply it to the analysis of ciders. Although 49 compounds were identified, our work was focused on the study of nine minor esters, obtaining recoveries ranging between $93 \%$ for ethyl decanoate and $117 \%$ for ethyl 3-methylbutyrate, and a precision (RSDs) ranging between $2.2 \%$ for hexyl acetate and ethyl decanoate and $10.9 \%$ for isopentyl acetate. To demonstrate the feasibility of the procedure, the method was applied to the analysis of commercial ciders.
\end{abstract}

(C) 2005 Elsevier B.V. All rights reserved.

Keywords: Cider; Purge and trap; Gas chromatography; Esters; Volatile

\section{Introduction}

The analysis of the volatile aroma constituents of food and beverages is one of the main tools employed to study the elaboration processes involved in food products, because of their influence on the final sensory properties. The study of these compounds have allowed to obtain reliable information about distinct stages in the manufacture process, such as the raw material used [1], fermentation process [2,3], and maturation and storage [4-6]. Gas chromatography (GC) involves the analysis of the volatile organic compounds exist in the vapor phase at the typical GC operating temperatures, between 40 and $300{ }^{\circ} \mathrm{C}$. In many cases, the levels of concentration are very low for direct analysis by gas chromatography, so that, several procedures have been proposed to isolate and concentrate aroma compounds prior to gas chromatography analysis in fermented beverages, with their advantages and drawbacks.

On the one hand, although the methods based on the extraction-concentration with organic solvents, like the clas-

\footnotetext{
* Corresponding author. Tel.: +34 985890066; fax: +34 985891854.

E-mail address: rrodriguez@serida.org (R. Rodríguez Madrera).
}

sical liquid-liquid extraction [7,8], present high liquid sample/solvent ratio, nevertheless these procedures are tedious and time consuming. More recently, Ferreira et al. [9] compared various liquid-liquid systems with solid-liquid extraction with distinct polymers in hydroalcoholic solutions, and Mangas et al. [10] described a solid-liquid extraction method for quantitate minor volatile compounds in cider.

A solid-phase microextraction (SPME) method was validated by Pozo-Bayón et al. [11] for the analysis of wines, and by Wang et al. [12] for apple juice and apple-wines; in both cases, the capacity of extraction depends on the polarity of fibres, being necessary to employ different fibres depending on the functional group of interest.

On the other hand, the techniques based on headspace concentration consist in the preconcentration of the vapour phase liberated from solid or liquid samples, and have been applied to many matrices and volatile compounds. These methods are non destructive, avoid the use of solvents, allow the isolation of volatile congeners in their natural form and present a minimum sample preparation. In the static headspace technique, the vapour phase is in equilibrium with the sample, so that these methods are only appropriate for volatile compounds highly concentrated in the headspace. In the dynamic 
headspace technique the equilibrium between the phases is continually altered. The purge and trap method (dynamic technique) is based on the bubbling through the sample (liquid or solid) with an inert gas (usually helium or nitrogen); volatile compounds are then adsorbed on a trap that is immediately heated to desorb them into a gas chromatograph injector. There are many adsorbents, such as the Porapaks, Chromosorbs or Tenax series, which meet the necessary requirements for correct thermal desorption; nevertheless the Tenax series (polymer based on 2,6-diphenyl-p-phenylene oxide) are quite appropriate for hydroalcoholic samples such as wine or analogous drinks [13]. In this sense, the use of purge and trap method has been proposed for analyzing fruits and fruit juices [14-16] and alcoholic beverages [2,13].

Numerically, fatty acid esters and acetic acid esters are the largest group of flavor compounds in alcoholic beverages, and as volatile compounds which impart pleasant smell, they are of great importance to the odor of the alcoholic beverages [17]. From the technological point of view, the presence of esters in alcoholic beverages is affected by the different stages involved in their manufacture such as fruit $[18,19]$, fermentation $[3,17]$ or maturation [20], therefore, the study of these compounds could contribute to improve the knowledge of the cider making.

With this in mind, the aim of this work is to develop a purge and trap method to quantify volatile esters in ciders. The parameters affecting the extraction of volatile compounds were evaluated and analytical parameters such as linearity, limit of detection, precision and accuracy were examined. Using the method optimized, the minor volatile esters were analyzed in a set of commercial ciders.

\section{Experimental}

\subsection{Samples}

Twenty natural ciders, purchased from market, were analyzed. All ciders were elaborated in Asturias (North of Spain) in distinct years: six samples elaborated in 2000, four samples elaborated in 2001 and 10 samples elaborated in 2003.

\subsection{Standards and reagents}

All standards were of analytical quality, with at least 97\% of purity. Isopentyl acetate, hexyl acetate, ethyl 3-methylbutyrate, ethyl hexanoate, and ethyl decanoate were supplied by Fluka (Busch, Switzerland), styrene by Merck (Darmstadt, Germany), and methyl acetate, ethyl octanoate, ethyl 2-methylbutyrate and ethyl butyrate by Aldrich (Madrid, Spain).

The standard work solutions were prepared by dilution of individual compounds in an ethanol/water mixture (5/95). The ethanol (HPLC quality) was purchased from Panreac (Barcelona, Spain) and the ultra pure water was obtained from a Milli-Q system from Millipore (Milford, USA).

\subsection{Purge and trap analysis}

A Tekmar 3100 Purge and Trap Concentrator equipment provided with a Teklink 3000 software (version 2.02) to control the headspace sampling was used. The trap employed was a Tenax (polymer of 2,6-diphenyl-p-phenylene oxide) supplied by Agilent Technologies (Palo Alto, CA, USA). Five milliliters of sample were introduced into the vessel and purged at $20^{\circ} \mathrm{C}$ during $30 \mathrm{~min}$ with helium at $50 \mathrm{~mL} / \mathrm{min}$. The trap was at room temperature while purging and then risen up to $230^{\circ} \mathrm{C}$ for desorption during $10 \mathrm{~min}$. A bake time of $20 \mathrm{~min}\left(230^{\circ} \mathrm{C}\right)$ was established for cleaning up the trap between analyses. The transfer line temperature was $300^{\circ} \mathrm{C}$.

\subsection{Standard curves and quantification}

Standard work solutions were extracted and desorbed as described before. The standard solutions were placed in the P\&T concentrator coupled to a Hewlett-Packard 5890 gas chromatograph equipped with a flame ionization detection (FID), a split/splitless injector and a HP 3365 series II ChemStation software (version A.03.04) for data processing. The separations were carried out on a FFAP capillary column $(50 \mathrm{~m} \times 0.22 \mathrm{~mm}$ i.d.; phase thickness, $0.33 \mu \mathrm{m})$ supplied from Tecknokroma (Barcelona, Spain). Chromatographic conditions were as follows: oven temperature, initial isotherm at $40^{\circ} \mathrm{C}(5 \mathrm{~min})$, raised up to $220^{\circ} \mathrm{C}$ at a rate of $3.0^{\circ} \mathrm{C} / \mathrm{min}$, and final isotherm of $220^{\circ} \mathrm{C}(5 \mathrm{~min})$; injector and detector temperature $250^{\circ} \mathrm{C}$; carrier gas, $\mathrm{He}$ at $1.5 \mathrm{~mL} / \mathrm{min}$; injection volume $1 \mu \mathrm{L}$. Split ratio 1/10.

External standard quantitation was used for all analyses. Linear regression analysis of areas versus concentration of volatile compounds in the standard solution was used. Equations for the standard curves are presented in Section 3 (Table 3).

\subsection{GC-MS analysis}

The identification of volatile compounds and the optimization of purge and desorption times were carried out with the P\&T system coupled to a Hewlett-Packard 5890 series II gas chromatograph equipped with a HP-5972 mass selective detector (quadrupole filter, source temperature $250^{\circ} \mathrm{C}$ ); the HP G1034C ChemStation software (version C.01.05) was used. Chromatographic conditions were as previously described (Section 2.4).

Mass spectra were recorded by the electron impact ionization (EI, $70 \mathrm{eV}$ ). The total ion mode (SCAN) was used for identification purposes in the range $m / z$ 40-400 $(2.6 \mathrm{scan} / \mathrm{s})$, and the selective ion mode (SIM) by using the most abundant and selective ions for evaluating the responses (Table 1). The identification of compounds was performed by comparing it with the Wiley $138 \mathrm{~K}$ Mass Spectral Database [21] and confirmed by co-injection of authentic standards whenever possible. 
Table 1

Effect of purging time on the efficacy of extraction with $10 \mathrm{~min}$ of desorption time and selected ions $(\mathrm{m} / \mathrm{z})$ used in the SIM mode

\begin{tabular}{|c|c|c|c|c|c|c|c|c|c|}
\hline \multirow[t]{3}{*}{ Compound } & \multirow[t]{3}{*}{$\mathrm{m} / \mathrm{z}$} & \multicolumn{8}{|l|}{ Purge time } \\
\hline & & \multicolumn{2}{|l|}{$10 \mathrm{~min}$} & \multicolumn{2}{|l|}{$20 \mathrm{~min}$} & \multicolumn{2}{|l|}{$30 \mathrm{~min}$} & \multicolumn{2}{|l|}{$40 \mathrm{~min}$} \\
\hline & & Mean $^{a}$ & $\overline{\operatorname{RSD}(\%)}$ & Mean $^{a}$ & $\overline{\operatorname{RSD}(\%)}$ & Mean $^{a}$ & $\operatorname{RSD}(\%)$ & Mean $^{a}$ & $\operatorname{RSD}(\%)$ \\
\hline \multicolumn{10}{|l|}{ Esters } \\
\hline Methyl acetate & 74 & $100.87 \mathrm{~b}$ & 2.5 & $188.68 \mathrm{~d}$ & 2.1 & $135.65 \mathrm{c}$ & 7.2 & $87.71 \mathrm{a}$ & 7.4 \\
\hline Isobutyl acetate & 73 & $28.07 \mathrm{a}$ & 9.9 & $43.43 \mathrm{~b}$ & 1.4 & $45.76 \mathrm{~b}$ & 6.4 & $48.49 \mathrm{~b}$ & 11.3 \\
\hline Ethyl butyrate & 88 & $128.24 \mathrm{a}$ & 3.4 & $224.15 b$ & 1.9 & $254.61 \mathrm{c}$ & 3.4 & $252.45 \mathrm{c}$ & 3.1 \\
\hline Ethyl 2-methylbutyrate & 102 & $244.60 \mathrm{a}$ & 2.0 & $355.04 \mathrm{c}$ & 1.4 & $339.83 \mathrm{c}$ & 3.5 & $306.46 \mathrm{~b}$ & 6.4 \\
\hline Isopentyl acetate & 70 & $1015.80 \mathrm{a}$ & 2.1 & $1085.88 \mathrm{a}$ & 7.4 & $1627.13 \mathrm{~b}$ & 2.6 & $1557.34 \mathrm{~b}$ & 6.0 \\
\hline Isopentyl propanoate & 70 & $169.90 \mathrm{a}$ & 2.2 & $222.42 \mathrm{c}$ & 2.2 & $217.58 \mathrm{c}$ & 1.7 & $196.59 \mathrm{~b}$ & 2.4 \\
\hline Ethyl hexanoate & 88 & $469.51 \mathrm{a}$ & 4.8 & $698.99 \mathrm{c}$ & 3.3 & $681.72 \mathrm{c}$ & 4.6 & $637.28 \mathrm{~b}$ & 1.4 \\
\hline Ethyl octanoate & 88 & $1062.75 \mathrm{a}$ & 0.8 & $1210.27 \mathrm{~b}$ & 2.6 & $1227.60 \mathrm{~b}$ & 5.0 & $1146.56 \mathrm{a}$ & 5.8 \\
\hline Ethyl decanoate & 88 & $323.13 \mathrm{~b}$ & 11.5 & $262.06 \mathrm{a}$ & 19.3 & $520.82 \mathrm{c}$ & 3.9 & $530.09 \mathrm{c}$ & 2.7 \\
\hline Ethyl lactate & 45 & $870.44 \mathrm{a}$ & 6.4 & $1393.07 \mathrm{~b}$ & 12.1 & $3162.90 \mathrm{c}$ & 8.7 & $4721.6 \mathrm{~d}$ & 4.9 \\
\hline Ethyl benzoate & 105 & $24.98 \mathrm{a}$ & 2.0 & $53.56 \mathrm{~b}$ & 7.2 & $90.77 \mathrm{c}$ & 1.5 & $118.57 \mathrm{~d}$ & 2.2 \\
\hline 2-Phenethyl acetate & 104 & $5.01 \mathrm{a}$ & 9.3 & $8.98 \mathrm{~b}$ & 8.0 & $19.63 \mathrm{c}$ & 9.6 & $31.68 \mathrm{~d}$ & 12.5 \\
\hline \multicolumn{10}{|l|}{ Alcohols } \\
\hline 2-Propen-1-ol & 57 & $156.51 \mathrm{a}$ & 2.1 & $339.17 \mathrm{c}$ & 4.4 & $359.21 \mathrm{c}$ & 4.6 & $313.14 \mathrm{~b}$ & 4.5 \\
\hline 1-Butanol & 56 & $295.79 \mathrm{a}$ & 3.0 & $583.02 \mathrm{~b}$ & 3.8 & $917.59 \mathrm{c}$ & 3.5 & $1212.68 \mathrm{~d}$ & 4.5 \\
\hline 1-Pentanol & 70 & $4.53 \mathrm{a}$ & 10.1 & $8.73 \mathrm{~b}$ & 18.8 & $14.80 \mathrm{c}$ & 5.0 & $19.06 \mathrm{~d}$ & 2.6 \\
\hline 1-Hexanol & 84 & $19.82 \mathrm{a}$ & 3.8 & $37.01 \mathrm{~b}$ & 9.6 & $62.92 \mathrm{c}$ & 4.5 & $82.24 \mathrm{~d}$ & 3.4 \\
\hline cis-3-Hexen-1-ol & 82 & $1.53 \mathrm{a}$ & 6.9 & $3.35 \mathrm{~b}$ & 5.2 & $5.68 \mathrm{c}$ & 7.9 & $7.52 \mathrm{~d}$ & 15.2 \\
\hline 1-Octanol & 84 & $6.23 \mathrm{a}$ & 6.4 & $12.79 \mathrm{~b}$ & 3.4 & $26.23 \mathrm{c}$ & 4.4 & $37.94 \mathrm{~d}$ & 4.00 \\
\hline 2-Phenylethanol & 91 & $43.36 \mathrm{a}$ & 3.6 & $90.65 \mathrm{~b}$ & 10.6 & $220.20 \mathrm{c}$ & 18.9 & $422.15 \mathrm{~d}$ & 14.4 \\
\hline \multicolumn{10}{|l|}{ Aldehydes } \\
\hline Benzaldehyde & 105 & $1.39 \mathrm{a}$ & 3.0 & $3.02 \mathrm{a}$ & 66.0 & $10.30 \mathrm{~b}$ & 11.9 & $13.34 \mathrm{c}$ & 10.9 \\
\hline \multicolumn{10}{|l|}{ Acids } \\
\hline Propanoic acid & 74 & $52.06 \mathrm{a}$ & 11.0 & $50.35 \mathrm{~b}$ & 53.5 & $443.03 \mathrm{c}$ & 37.1 & $1078.48 \mathrm{~d}$ & 12.7 \\
\hline \multicolumn{10}{|l|}{ Hydrocarbons } \\
\hline Styrene & 104 & $82.82 \mathrm{~b}$ & 2.2 & $100.22 \mathrm{a}$ & 2.8 & $72.20 \mathrm{c}$ & 4.1 & $53.99 \mathrm{~d}$ & 16.5 \\
\hline
\end{tabular}

RSD: Relative standard deviation (three replicates). Letters $\mathrm{a}, \mathrm{b}, \mathrm{c}$ and $\mathrm{d}$ are used to compare mean values within each row, indicating significantly different results according to Duncan's test.

a Expressed in area $\times 10^{-4}$.

\subsection{Statistical methods}

Analysis of variance (ANOVA) and Duncan's test were carried out for detecting significant differences either in the analyte concentrations depending on purge and desorption time or among cider samples. Linear regressions were carried out in the calibration procedure and the recovery study. The program used was SPSS [22].

\section{Results and discussion}

\subsection{Optimization of extraction conditions}

The two main variables that account for extraction efficiency of an analyte using the purge and trap technique are total extraction volume and sample temperature.

Respect to the temperature, although sample heating improved the purging efficiency, temperatures higher than $30^{\circ} \mathrm{C}$ can alter original characteristics of cider [13]; thus, it was set at $20^{\circ} \mathrm{C}$.
The total extraction volume, or total volume of purging gas passed through the sample during the extraction, is determined by multiplying the purge flow rate by the purge time. This effect can be studied by increasing either the purge time under constant flow rate or the purge flow rate. We have selected the effect of purging time under a constant flow for optimizing the total extraction volume.

\subsubsection{Purge time}

Five milliliters of the same cider sample were introduced into the vessel and purged at $20^{\circ} \mathrm{C}$ during $10,20,30$ and $40 \mathrm{~min}$ with helium $(50 \mathrm{~mL} / \mathrm{min})$. The trap was at room temperature while purging and then risen up at $230^{\circ} \mathrm{C}$ for desorption during $10 \mathrm{~min}$. Therefore, the transfer line was set at $300^{\circ} \mathrm{C}$ to prevent the condensation of the less volatile compounds. A bake time of $20 \mathrm{~min}\left(230^{\circ} \mathrm{C}\right)$ was established for cleaning up the trap between analysis.

The effect of the extraction time was evaluated by comparing the areas of the volatile compounds identified in the cider by the GC-MS analysis versus purging time. Table 1 shows the mean and relative standard deviation values of the 


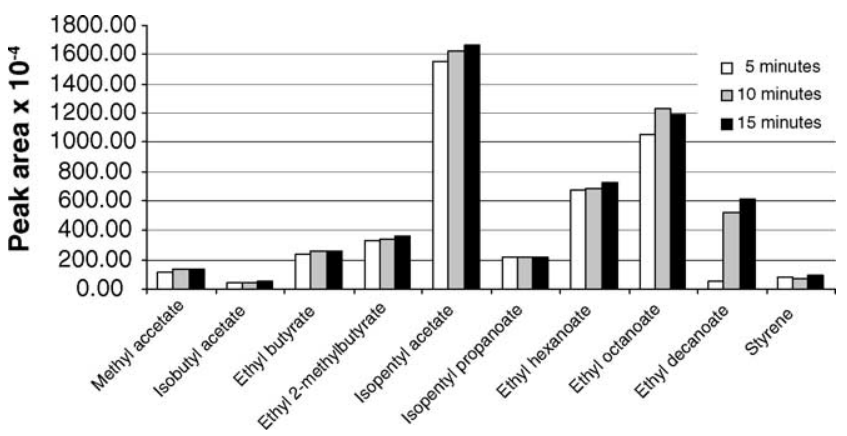

Fig. 1. Effect of desorption time on the extraction efficacy for styrene and esters with $30 \mathrm{~min}$ of purging time.

volatile compounds extracted from cider analyzed under the above conditions.

As can be seen in Table 1, the amount of analyte depended on the extraction time, which could be explained on the basis of hydrogen bonding and the physical properties of compounds [23]. In general, compounds that are capable of establishing strong hydrogen bonding with the matrix and compounds with high boiling points (such as alcohols, acids, benzaldehyde, and the esters 2-phenylethyl acetate, ethyl benzoate and ethyl lactate) need the greatest purge time for the extraction. The rest of esters were extracted in 20-30 min, that could be explained by their low boiling points and also by the absence of hydrogen bonding with water. Nevertheless, the decrease in the concentration of these esters at $40 \mathrm{~min}$ could be attributed to a purging volume higher than the breakthrough volume for these analytes $[24,25]$. Therefore, after the evaluation of the results, a purging time of $30 \mathrm{~min}$ was selected to optimize the method for the analysis of minor esters.

\subsubsection{Desorption time}

Maintaining the purging time at $30 \mathrm{~min}$, we have tested the three different desorption times $(5,10$ and $15 \mathrm{~min})$ to liberate the analytes of interest.

As shown in Fig. 1, this parameter was not as critical as purging time, many volatiles being completely desorbed after $5 \mathrm{~min}$. However, a significant influence of this parameter was observed for methyl acetate, ethyl butyrate, ethyl octanoate and ethyl decanoate, although these differences were never higher than $20 \%$, excepting for ethyl decanoate. The great difference observed for this compound between 5 and 10 min (more than 90\%) could be explained by its boiling point $\left(245^{\circ} \mathrm{C}\right)$, which is slightly higher than the desorption temperature $\left(230^{\circ} \mathrm{C}\right)$. Thus, a desorption time of $10 \mathrm{~min}$ was finally chosen.

A total of 49 volatile components were detected in the distinct ciders analyzed by the P\&T and GC-MS under the optimized conditions (Table 2). These compounds were mainly esters, alcohols and in a lesser amount, fatty acids, carbonyls, hydrocarbons, terpenes and phenolics derivatives. In Fig. 2 is displayed a chromatogram obtained with the final conditions.

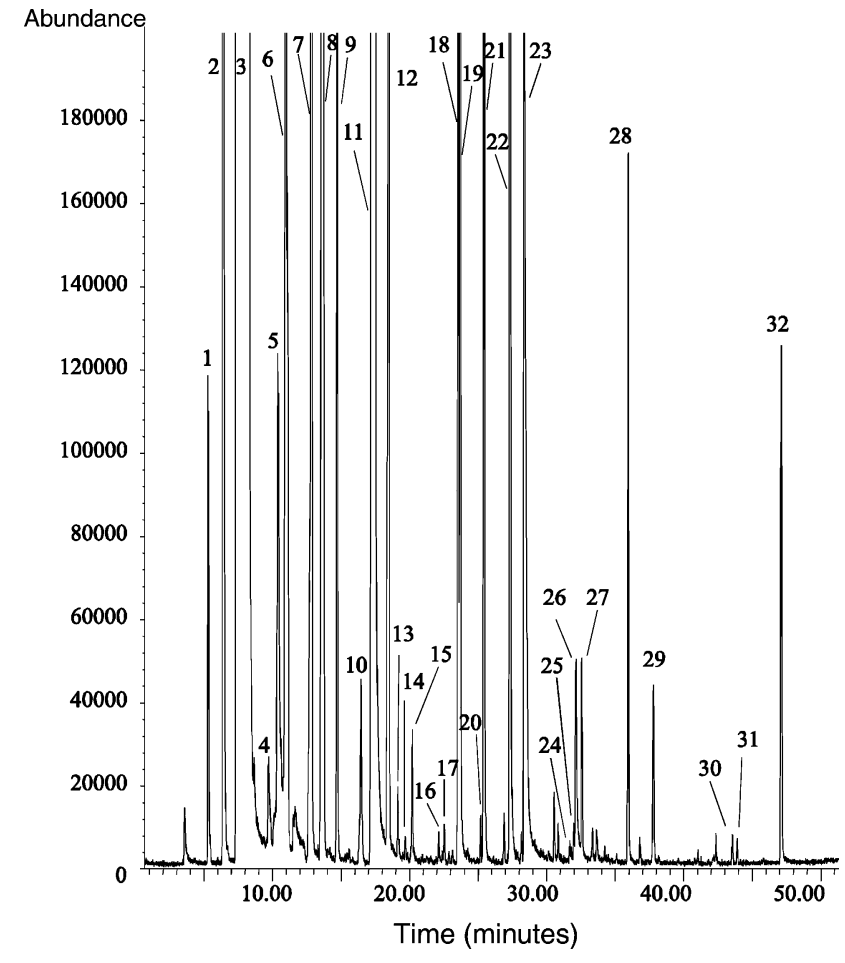

Fig. 2. GC-MS chromatogram (scan mode) of a cider extract: $1=$ methyl acetate; $2=$ ethyl acetate; $3=$ ethanol; $4=$ ethyl butyrate; $5=$ ethyl 2-methylbutyrate; $\quad 6=1$-propanol; $\quad 7=$ isobutanol; $\quad 8=3$-methylbutyl acetate; $9=1$-butanol; $10=3$-methylbutyl propanoate; $11=3$-methyl1-butanol +2-methyl-1-butanol; $12=$ ethyl hexanoate; $13=1$-pentanol; $14=$ styrene; $15=$ hexyl acetate; $16=2$-heptanol; $17=3$-methyl-1-pentanol; $18=$ ethyl lactate; $19=1$-hexanol; $20=Z-3$-hexen-1-ol; $21=$ methyl octanoate; $22=$ ethyl octanoate; $23=$ acetic acid; $24=$ unknown terpene; $25=$ benzaldehyde; $26=$ propanoic acid; $27=1$-octanol; $28=$ ethyl decanoate; $29=$ ethyl benzoate; $30=2$-phenylethyl acetate; $31=$ ethyl dodecanoate; $32=2$-phenylethanol.

\subsection{Method validation and quantification}

To check the linearity of the detector response a linear regression analysis of absolute areas versus concentration of volatile compounds (three replicates at five points) was used. The standard work solutions were extracted and desorbed in the optimized conditions described in Section 2.3. Ranges and linear regression statistics are shown in Table 3. An adequate linearity was obtained for all analytes, with $R^{2}$ values ranging from 0.944 to 0.999 . The limits of detection (LODs) were estimated for each compound as the concentration corresponding to the mean area of three blank injections plus three times the standard deviation [26]. To inspect the goodness of the fit for the linear regression, or said in other way, in order to detect the lack of fit, a model was tested by computing the statistic $F$, defined as the quotient between mean squares of lack of fit and mean squares of pure experimental error [27]. The null hypothesis (a linear model is appropriate) was always accepted, therefore, the regression for all the analytes studied can be considered as a straight line, even when less variance was explained (lower values for $R^{2}$ ). The $F$ statistic 
Table 2

Compounds identified in ciders with the optimized conditions for purge and trap concentrator

\begin{tabular}{|c|c|c|c|}
\hline Compound & Retention time (min) & Identification & Descriptor $^{\mathrm{a}}$ \\
\hline Acetaldehyde & 4.1 & $\mathrm{~S}$ & Pungent [31] \\
\hline Methyl acetate & 5.3 & $\mathrm{~S}$ & Solvent, sweet $[32,35]$ \\
\hline 2-Propenal & 5.6 & $\mathrm{~S}$ & Peppery [33] \\
\hline Ethyl acetate & 6.1 & $\mathrm{~S}$ & Solvent, fruity [32] \\
\hline Butanone & 6.4 & MS & Ether [31] \\
\hline Ethyl propanoate & 8.5 & $\mathrm{~S}$ & Fruity, sweet [31,35] \\
\hline Isobutyl acetate & 9.4 & $\mathrm{~S}$ & Fruit, apple [31,32] \\
\hline Ethyl butyrate & 10.1 & $\mathrm{~S}$ & Fruity, sweet $[28,34]$ \\
\hline 2-Butanol & 10.5 & $\mathrm{~S}$ & Wine, solvent [31] \\
\hline Ethyl 2-methylbutyrate & 10.7 & $\mathrm{~S}$ & Cider, fruity [12,34] \\
\hline 1-Propanol & 10.9 & $\mathrm{~S}$ & Alcohol, ripe fruit $[31,32]$ \\
\hline Ethyl 3-methylbutyrate & 11.2 & $\mathrm{~S}$ & Fruity, balsamic [31] \\
\hline Isobutanol & 12.8 & $\mathrm{~S}$ & Solvent, wine [31] \\
\hline 3-Methylbutyl acetate & 13.2 & $\mathrm{~S}$ & Banana $[31,34]$ \\
\hline 2-Propen-1-ol & 13.6 & $\mathrm{~S}$ & - \\
\hline 1-Butanol & 14.6 & $\mathrm{~S}$ & Chemical, heavy [28] \\
\hline 3-Methylbutyl propanoate & 16.1 & MS & Pineapple [31] \\
\hline 3-Methyl-1-butanol + 2-methyl-1-butanol & 17.0 & $\mathrm{~S}$ & Malt, burnt [31] \\
\hline Ethyl hexanoate & 18.1 & $\mathrm{~S}$ & Apple peel, fruit $[31,35]$ \\
\hline 1-Pentanol & 19.0 & $\mathrm{~S}$ & Balsamic [31] \\
\hline Styrene & 19.3 & $\mathrm{~S}$ & Balsamic, gasoline [31] \\
\hline Hexyl acetate & 20.1 & $\mathrm{~S}$ & Green, herbaceous $[31,35]$ \\
\hline Acetoin & 20.2 & $\mathrm{~S}$ & Butter [32] \\
\hline 1,1,3-Triethoxypropane & 21.4 & S & Floral, vegetal [34] \\
\hline 2-Heptanol & 22.0 & MS & Mushroom [5] \\
\hline 3-Methyl-1-pentanol & 22.5 & MS & Winelike, green [37] \\
\hline Hexyl propanoate & 22.8 & MS & Apple [19] \\
\hline Ethyl lactate & 23.4 & $\mathrm{~S}$ & Soapy [36] \\
\hline 1-Hexanol & 23.7 & $\mathrm{~S}$ & Green, grass [31,32] \\
\hline Z-3-Hexen-1-ol & 25.1 & $\mathrm{~S}$ & Green, herbaceous [32] \\
\hline Methyl octanoate & 25.4 & $\mathrm{~S}$ & Orange [31] \\
\hline Ethyl octanoate & 27.3 & $\mathrm{~S}$ & Fruit [31] \\
\hline Acetic acid & 28.6 & $\mathrm{~S}$ & Vinegar [19] \\
\hline Furfural & 29.2 & $\mathrm{~S}$ & Caramel, sweet [31] \\
\hline 2-Nonanol & 30.8 & MS & Cucumber [31] \\
\hline Unknown terpene 1 & 31.6 & MS & - \\
\hline Unknown terpene 2 & 31.7 & MS & - \\
\hline Benzaldehyde & 31.9 & $\mathrm{~S}$ & Almond [31] \\
\hline Propanoic acid & 32.2 & $\mathrm{~S}$ & Pungent, rancid [31] \\
\hline 1-Octanol & 32.7 & $\mathrm{~S}$ & Oily, fatty [28] \\
\hline Ethyl decanoate & 36.1 & $\mathrm{~S}$ & Grape [32] \\
\hline Ethyl benzoate & 37.7 & $\mathrm{~S}$ & Flower, fruit [31] \\
\hline Diethyl succinate & 37.9 & $\mathrm{~S}$ & Fruit, wine [31] \\
\hline 1-Decanol & 40.8 & MS & Fat [31] \\
\hline Naphthalene & 41.0 & MS & $\operatorname{Tar}[31]$ \\
\hline 2-Phenylethyl acetate & 43.6 & $\mathrm{~S}$ & Rose, floral [32] \\
\hline Ethyl dodecanoate & 43.9 & $\mathrm{~S}$ & Leaf [31] \\
\hline 2-Phenylethanol & 47.2 & $\mathrm{~S}$ & Rose, floral [35] \\
\hline$p$-Hydroxybenzoic acid & 50.6 & MS & - \\
\hline
\end{tabular}

MS: Mass spectrometry identification (match quality>90\%); S: verified with pure standard.

a Numbers according to References section.

calculated for detecting the lack of fit was contrasted with the tabulated value using a $95 \%$ confidence level.

Recovery experiments were performed in order to study the precision and accuracy of the method described. Known amounts of pure standards methyl acetate, ethyl butyrate, ethyl 2-methylbutyrate, ethyl 3-methylbutyrate, isopentyl acetate, hexyl acetate, ethyl hexanoate, ethyl octanoate, ethyl decanoate and styrene were added to a cider and the resulting spiked sample were subjected to the entire analyt- ical sequence. Each compound was added at three different concentrations and three replicate were analyzed at each level. Recoveries were calculated on the basis of the difference between the total amount determined in the spiked samples and the amount determined in the non-spiked samples divided by the amount added. The average recoveries ranged between $93 \%$ for ethyl decanoate and $117 \%$ for ethyl 3-methylbutyrate, while the average value for all of the compounds studied is $102 \%$ (Table 3 ). 
Table 3

Calibration curves, recovery study and limit of detection

\begin{tabular}{|c|c|c|c|c|c|c|c|c|c|c|c|}
\hline \multirow[t]{2}{*}{ Compounds } & \multicolumn{6}{|c|}{ Linear regression } & \multicolumn{4}{|c|}{ Recoveries } & \multirow{2}{*}{$\begin{array}{l}\text { LOD } \\
(\mathrm{mg} / \mathrm{L})\end{array}$} \\
\hline & $\begin{array}{l}\text { Range } \\
(\mathrm{mg} / \mathrm{L})\end{array}$ & $a$ & $b$ & $R^{2}$ & $a_{\min }$ & $a_{\max }$ & $a$ & $R^{2}$ & $\begin{array}{l}\text { Recovery } \\
(\%)\end{array}$ & $\begin{array}{l}\operatorname{RSD}(\%) \\
(n=3)\end{array}$ & \\
\hline Methyl acetate ${ }^{a}$ & $0-0.932$ & 9735 & 57 & 0.998 & 9410 & 10059 & 10462 & 0.993 & 107 & 8.9 & 0.020 \\
\hline Ethyl butyrate ${ }^{\mathrm{a}}$ & $0-1.740$ & 20527 & -199 & 0.996 & 19371 & 20527 & 22238 & 0.993 & 100 & 10.4 & 0.026 \\
\hline Ethyl 2-methylbutyrate & $0-0.869$ & 31939 & -227 & 0.998 & 31066 & 32813 & 33255 & 0.991 & 99 & 8.2 & 0.016 \\
\hline Ethyl 3-methylbutyrate & $0-1.724$ & 44049 & -251 & 0.999 & 42862 & 45237 & 57970 & 0.986 & 117 & 10.3 & 0.012 \\
\hline Isopentyl acetate & $0-1.742$ & 58665 & -2433 & 0.999 & 57399 & 60570 & 74459 & 0.974 & 112 & 10.9 & 0.048 \\
\hline Hexyl acetate ${ }^{a}$ & $0-1.746$ & 154227 & -4108 & 0.999 & 151386 & 157068 & 148191 & 0.995 & 97 & 2.2 & 0.027 \\
\hline Ethyl hexanoate $^{\mathrm{a}}$ & $0-1.742$ & 146845 & -7145 & 0.998 & 141838 & 151851 & 147006 & 0.994 & 104 & 2.9 & 0.051 \\
\hline Ethyl octanoate ${ }^{\mathrm{a}}$ & $0-1.756$ & 259025 & -14949 & 0.994 & 245430 & 272621 & 248051 & 0.990 & 97 & 6.1 & 0.060 \\
\hline Ethyl decanoate ${ }^{a}$ & $0-1.728$ & 191854 & -22460 & 0.944 & 144962 & 238747 & 175543 & 0.989 & 93 & 2.2 & 0.122 \\
\hline Styrene ${ }^{\mathrm{a}}$ & $0-1.000$ & 87211 & -201 & 0.999 & 85803 & 88618 & 88944 & 0.999 & 94 & 8.9 & 0.005 \\
\hline
\end{tabular}

$a$ : Slope; $b$ : intercept; $R^{2}$ : coefficient of regression. Recovery is the mean of three levels; $a_{\max }$ and $a_{\min }$ are the values for a 95\% of confidence interval; LOD: limit of detection.

${ }^{\text {a }}$ Significant differences were detected between slopes from calibration and recovery linear regression.

Precision was studied in a real sample for peak areas. The repeatability of peak areas was calculated by the RSD of three injections carried out on the same day. The RSD ranged between $2.2 \%$ for hexyl acetate and ethyl decanoate and $10.9 \%$ for isopentyl acetate, with an average value of $7.1 \%$ (Table 3). The reproducibility of the method was evaluated during recovery experiments and the RSD were always $<11 \%$.

The slopes of the regression line obtained in the recovery experiments and those of the calibration lines obtained with standard solution not differ statistically for methyl acetate, ethyl butyrate, ethyl 2-methylbutyrate, hexyl acetate, ethyl hexanoate, ethyl octanoate, ethyl decanoate and styrene. Therefore, no systematic errors were caused by the fact that the calibration curve were obtained with $5 \%$ ethanol model solutions.

\subsection{Cider samples analysis}

The P\&T technique was applied to the analysis of 20 ciders purchased from the market and belonging to three harvest years. Table 4 resumes the analysis carried out for the three groups established.

The one-way ANOVA showed significant differences for 4 of the 10 variables determined in the samples. These differences were detected for methyl acetate $(p=0.008)$, ethyl 2-methylbutyrate $(p<0.001)$, ethyl butyrate $(p=0.019)$ and ethyl hexanoate $(p=0.001)$ (Table 4$)$. The higher levels detected for ethyl butyrate, a fruity aroma [28], and ethyl 2methylbutyrate, defined as cider odor [12], in the ciders elaborated in the harvests 2000 and 2001 (Table 4) could be favored by longer periods of maturation, as observed in Sherry $[20,29]$. The higher levels of methyl acetate found in these samples (Table 4) could be also explained in this way, as a consequence of the esterification of acetic acid with methanol. Ethyl hexanoate, also imparts fruity notes, although in this case, the differences detected among harvests cannot be associated to maturation periods but to fermentative processes and the yeast strains involved according to previous works [17,30]; in this sense, the levels of ethyl esters of the fatty acids studied were in agreement with these obtained in apple wine by using other analytical methods [12].

Table 4

Concentration of esters and styrene in natural ciders

\begin{tabular}{|c|c|c|c|c|c|c|c|c|c|c|c|c|}
\hline \multirow[t]{2}{*}{ Compounds } & \multicolumn{4}{|c|}{ Harvest $2000(n=6)$} & \multicolumn{4}{|c|}{ Harvest $2001(n=4)$} & \multicolumn{4}{|c|}{ Harvest $2003(n=10)$} \\
\hline & $\begin{array}{l}\text { Mean } \\
(\mathrm{mg} / \mathrm{L})\end{array}$ & $\begin{array}{l}\mathrm{SD} \\
(\mathrm{mg} / \mathrm{L})\end{array}$ & $\begin{array}{l}\operatorname{Max} \\
(\mathrm{mg} / \mathrm{L})\end{array}$ & $\begin{array}{l}\text { Min } \\
(\mathrm{mg} / \mathrm{L})\end{array}$ & $\begin{array}{l}\text { Mean } \\
(\mathrm{mg} / \mathrm{L})\end{array}$ & $\begin{array}{l}\mathrm{SD} \\
(\mathrm{mg} / \mathrm{L})\end{array}$ & $\begin{array}{l}\operatorname{Max} \\
(\mathrm{mg} / \mathrm{L})\end{array}$ & $\begin{array}{l}\text { Min } \\
(\mathrm{mg} / \mathrm{L})\end{array}$ & $\begin{array}{l}\text { Mean } \\
(\mathrm{mg} / \mathrm{L})\end{array}$ & $\begin{array}{l}\mathrm{SD} \\
(\mathrm{mg} / \mathrm{L})\end{array}$ & $\begin{array}{l}\operatorname{Max} \\
(\mathrm{mg} / \mathrm{L})\end{array}$ & $\begin{array}{l}\text { Min } \\
(\mathrm{mg} / \mathrm{L})\end{array}$ \\
\hline Methyl acetate ${ }^{\mathrm{a}}$ & 0.75 & 0.14 & 0.93 & 0.52 & 0.88 & 0.68 & 1.88 & 0.41 & 0.27 & 0.21 & 0.83 & 0.07 \\
\hline Ethyl butyrate $^{\mathrm{a}}$ & 0.14 & 0.08 & 0.21 & 0.00 & 0.26 & 0.08 & 0.38 & 0.19 & 0.16 & 0.04 & 0.21 & 0.10 \\
\hline Ethyl 2-methylbutyrate ${ }^{a}$ & 0.14 & 0.06 & 0.24 & 0.08 & 0.16 & 0.05 & 0.23 & 0.13 & 0.03 & 0.02 & 0.06 & 0.00 \\
\hline Ethyl 3-methylbutyrate & 0.01 & 0.02 & 0.06 & 0.00 & 0.02 & 0.02 & 0.04 & 0.00 & 0.01 & 0.02 & 0.05 & 0.00 \\
\hline Isopentyl acetate & 0.85 & 0.26 & 1.20 & 0.57 & 1.08 & 0.37 & 1.52 & 0.62 & 0.84 & 0.40 & 1.49 & 0.46 \\
\hline Hexyl acetate & 0.06 & 0.01 & 0.07 & 0.05 & 0.07 & 0.02 & 0.08 & 0.05 & 0.05 & 0.02 & 0.08 & 0.03 \\
\hline Ethyl hexanoate $^{a}$ & 0.47 & 0.13 & 0.65 & 0.30 & 0.57 & 0.05 & 0.65 & 0.54 & 0.32 & 0.09 & 0.44 & 0.16 \\
\hline Ethyl octanoate & 1.29 & 0.71 & 2.13 & 0.39 & 0.83 & 0.40 & 1.39 & 0.44 & 1.10 & 0.58 & 2.03 & 0.19 \\
\hline Ethyl decanoate & 0.83 & 0.40 & 1.42 & 0.22 & 0.59 & 0.51 & 1.34 & 0.24 & 0.75 & 0.51 & 1.49 & 0.17 \\
\hline Styrene & 0.01 & 0.01 & 0.02 & 0.01 & 0.01 & 0.01 & 0.02 & 0.01 & 0.02 & 0.01 & 0.03 & 0.01 \\
\hline
\end{tabular}

a Significant differences were detected between groups $(p<0.05)$. 


\section{Conclusion}

The analytical method proposed permits the determination of esters and styrene in ciders without sample treatment with a good degree of reproducibility and accuracy. Furthermore, the method could be used for qualitative determination of other volatiles in cider. The application of this method to the analysis of commercial ciders could be an effective tool for the study of the technical processes that influence cider making.

\section{Acknowledgements}

The authors are indebted to the Comisión Interministerial de Ciencia y Tecnología (CICYT AGL2001-0713) and the Government of Principado de Asturias for financial support.

\section{References}

[1] J.L. Aleixandre, V. Lizama, I. Alvarez, M.J. Garcia, J. Agric. Food Chem. 50 (2002) 751.

[2] B. Girard, T.G. Kopp, A.G. Reynolds, M. Cliff, Am. J. Enol. Vitic. 48 (1997) 198.

[3] E. Vianna, S.E. Ebeler, J. Agric. Food Chem. 49 (2001) 589.

[4] B. Siegmunnd, K. Derler, W. Pfannhauser, J. Agric. Food Chem. 49 (2001) 3244

[5] S.G. Fu, Y. Yoon, R. Bazemore, J. Agric. Food Chem. 50 (2002) 549.

[6] A.L. Waterhouse, J.P. Towney, J. Agric. Food Chem. 42 (1994) 1971.

[7] T. Herraiz, G. Reglero, P.J. Martín-Álvarez, M. Herraiz, M.D. Cabezudo, J. Sci. Food Agric. 55 (1991) 103.

[8] J. Marais, A.C. Houtman, Am. J. Enol. Vitic. 30 (1979) 250.

[9] V. Ferreira, L. Ortega, A. Escudero, J.F. Cacho, J. Chromatogr. Sci. 38 (2000) 469.

[10] J.J. Mangas, M.P. González, R. Rodríguez, D. Blanco, Chromatographia 42 (1996) 101.

[11] M.A. Pozo-Bayón, E. Pueyo, P.J. Martín-Álvarez, M.C. Polo, J. Chromatogr. A 992 (2001) 267.

[12] L. Wang, Y. Xu, G. Zhao, J. Li, J. Inst. Brew. 110 (2004) 57.
[13] M.R. Salinas Fernández, G.L. Alonso-Díaz-Marta, in: H.F. Linskens, J.F. Jackson (Eds.), Modern Methods of Plant Analysis, vol. 19, Plant Volatile Analysis, Berlin, Germany, 1997, p. 175.

[14] M.G. Moshonas, P.E. Shaw, J. Agric. Food Chem. 45 (1997) 3968.

[15] M.A. Hakala, A.T. Lapveteläinen, H.P. Kallio, J. Agric. Food Chem. 50 (2002) 1133.

[16] F. Ruiz-Beviá, A. Font, A.N. García, P. Blasco, J.J. Ruiz, J. Sci. Food Agric. 82 (2002) 1182.

[17] L. Nykänen, Am. J. Enol. Vitic. 37 (1986) 84.

[18] P. Dirinck, H. de Pooter, N. Schamp, in: R. Teranishi, R.G. Buttery, F. Shadidi (Eds.), Flavor Chemistry: Trends and Developments, third ed., Toronto, Ontario, 1988, p. 23.

[19] A. Plotto, M.R. McDaniel, J. Am. Soc. Hort. Sci. 125 (2000) 714.

[20] M.S. Kung, G.F. Russell, B. Stackler, A.D. Webb, Am. J. Enol. Vitic. 31 (1980) 187.

[21] J. Wiley, Wiley 138 Spectral Database, 1990.

[22] SPSS Advanced Statistics 6.1, SPSS Inc, Chicago, IL, 1994.

[23] D.P. Lin, C. Falkenberg, D.A. Payne, J. Thakkar, C. Tang, C. Elly, Anal. Chem. 65 (1993) 999.

[24] S.M. Abeel, A.K. Vickers, D. Decker, J. Chromatogr. Sci. 32 (1994) 328.

[25] T.P. Wampler, in: R. Marsili (Ed.), Techniques for Analyzing Food Aroma, Marcel Dekker Inc., New York, 1997, p. 27.

[26] IUPAC, Spectrochim. Acta 33B (1978) 242.

[27] R. Lyman Ott, An Introduction to Statistical Methods and Data Analysis, fourth ed., Duxbury Press/Wadsworth Publ., Belmont, CA, 1993.

[28] A. Dravnieks, Atlas of Odor Character Profiles, American Society of Testing and Materials, Baltimore, MD, 1985.

[29] M.B. Cortés, J.J. Moreno, L. Zea, L. Moyano, M. Medina, J. Agric. Food Chem. 47 (1999) 3297.

[30] J.J. Moreno, C. Millán, J.M. Ortega, M. Medina, J. Ind. Microbiol. 7 (1991) 181.

[31] T. Acree, H. Arn, Published on line at http://www.nysaes.cornell. edu/flavornet, Cornell University, Geneve, NY, 1997, Accesses 19 January 2005.

[32] R.A. Peinado, J. Moreno, J.E. Bueno, J.A. Moreno, J.C. Mauricio, Food Chem. 84 (2004) 585.

[33] P.J. Williams, C.R. Strauss, J. Sci. Food Agric. 26 (1975) 1127.

[34] J. Ledauphin, H. Guichard, J.-F. Saint-Clair, B. Picoche, D. Barillier, J. Agric. Food Chem. 61 (2003) 433.

[35] C. Varming, M.A. Petersen, L. Poll, J. Agric. Food Chem. 52 (2004) 1647.

[36] V. Ferreira, Nuevas aportaciones a la quimica analítica del aroma del vino, Ph.D. Thesis, University of Zaragoza, 1992.

[37] L. Moyano, L. Zea, J. Moreno, M. Medina, J. Agric. Food Chem. 50 (2002) 7356. 